\title{
Why Has Japanese Educational Reform Come to a De Facto End?
}

\author{
Mamiko Takeuchi ${ }^{1}$ \\ ${ }^{1}$ Office for the Promotion of Gender Equality, Kyushu University, Fukuoka, Japan \\ Correspondence: Mamiko Takeuchi, Office for the Promotion of Gender Equality, Kyushu University, 744 \\ Motooka Nishi-ku Fukuoka 819-0395, Japan. E-mail: takeuchi@danjyo.kyushu-u.ac.jp
}

Received: January 13, 2019 Accepted: March 1, 2019 Online Published: March 29, 2019

doi:10.5539/jel.v8n3p13

URL: https://doi.org/10.5539/jel.v8n3p13

\begin{abstract}
A reform of public education in Japan took place from the 1980s, coming to a de facto end in 2013. The reform, which affected large numbers of Japanese children, focused on creating a more flexible, relaxed form of education by reducing the amount included in the curriculum. However, the effects of this reform have been ambiguous, and we therefore aimed to assess them more accurately. We assessed the effects of the reform by looking at the private educational costs of households during the reform period, using the data from a time series survey conducted by the Japanese government. Our evidence shows that the auxiliary study expenses of children in public junior high schools increased steadily, and the proportion of children from households in the highest income group attending private junior high schools also rose during the reform period. This evidence indicates that the reform had unexpected results. It may have triggered a widening of children's academic ability gap depending on household wealth. There is also no comprehensive evaluation of how pressure-free education affected the academic results of Japanese children. We drew some lessons from this experience to suggest what is needed for successful educational reform.
\end{abstract}

Keywords: academic standards, educational reform, private educational cost, publicly-funded schools

\section{Introduction}

The creation of a more flexible, relaxed form of education was the focus of reforms in compulsory public education in Japan starting in the 1980s, and coming to a de facto end in 2013. The objective of these educational reforms was to make children's lives more relaxed and to develop so-called "skills for life".

The reform involved three main changes: a five-day week school system, "hours of comprehensive learning", and evaluation on an absolute (rather than relative) scale. The students whose education featured all or part of these reforms have been called the "generation of relaxed education", and were those born between April 2, 1987, and April 1, 2004. The effects, however, were ambiguous. Some researchers have pointed out that academic standards declined during the reform period. Educational reforms may also affect private educational expenses through household budgetary constraints and children's time constraints.

Leibowitz (1974) and Haveman and Wolfe (1995) examined the influence of parental behavior and family environment on children's educational outcomes. They suggested that parental educational investment is particularly important. In Japan, Hojo (2011) and Hojo and Oshio (2010) showed that family environment, rather than factors related to the school, had the greatest effect on academic ability.

In Japan, some private junior high schools operate a six-year education program in partnership with high schools. They therefore serve as preparatory schools for college entrance examinations. Admission to a high school with high academic scores is important for children who wish to attend good universities. Some researchers have therefore examined the effect of reforms on the households of junior high school students. Kikuchi (2014) found that a reduction in instructional time reduced the probability of students attending high school, but did not affect their probability of attending college. Kubota (2016) showed that the 2002 educational reforms increased target household expenditure on supplementary education and out-of-school activities. This research focused on households with children attending junior high school. We therefore examined the educational reform by looking at private educational costs across elementary schools, junior high schools and high schools, to assess the comparative effect of these educational reforms. 


\section{Educational Reform in Japan}

Discussion about the five-day school week emerged from a broader argument about the five-day working week, which began in the 1970s (Note 1, Yamamoto \& Muto, 1992). In 1980, "leisure time", or time involving no teaching, was expanded in publicly-funded Japanese schools, and the five-day school week, with the second Saturday of every month as a special holiday, was introduced into all public schools in 1992 (Ministry of Education, Culture, Sports, Science and Technology [MEXT], 1992). This reform specified instructional research areas, with the cooperation of schools and communities. Five-day weeks were implemented twice a month starting in 1995, alongside a reduction in the school curriculum and improvement of educational powers in the home and the community. A five-day week became standard in all Japanese public schools in 2002 (MEXT, 2009).

Curriculum improvements were introduced together with defined hours of comprehensive learning and evaluation on an absolute scale. The curriculum content, and hence the time required, were reduced by 30 percent. Private schools were not required to offer a five-day week, although Ministry of Education, Culture, Sports, Science and Technology (MEXT) encouraged its gradual adoption. Private secondary schools (junior high and high schools, covering six years of secondary education), however, especially in metropolitan areas, have largely refused to adopt this system (Note 2, Education Development Information Center, 2002).

According to MEXT (1996), the purpose of the introduction of the five-day school week was to reexamine the role of education in schools, at home, and in the community (Note 3). A secondary aim was to train children to live in a changing society and meet the needs of the future society. With the increase in computerization and internationalization of society in the 21 st century, and the expectation of further rapid change, children are expected to need very different skills in the future, including improved life skills. A five-day school week aims to raise students' capability to find information themselves, and explore the world through experience (MEXT, 1996).

The resulting drastic reduction in learning time has, however, led to the possible new problems of increased educational expenses for households and decline in academic achievement. The issue of an academic ability fall was aggravated by the introduction of the five-day school week. Data from the Program for International Student Assessment (PISA) for 2000, 2003, and 2006 (National Institute of Educational Policy Research [NIEPR], 2000, 2003, 2006) show a decline for Japan compared with other Organisation of Economic Co-operation and Development (OECD) countries. Tables 1-3 present the PISA rankings for three abilities: reading capacity, mathematical literacy, and scientific literacy in OECD countries.

Table 2 shows that Japan fell from first to 10th in terms of mathematical literacy from 2000 to 2006 . That was later referred to as the "PISA Shock" by the mass media, and it triggered further revision of the whole education system (Asahi Newspaper, 2007). Rankings with the other two abilities also suffered a decline from 2000 to 2006 (Tables 1, 3). Trends in International Mathematics and Science Study (TIMSS) for 2003 (NIEPR, 2003) likewise indicated a decline for Japan compared with other OECD countries. As a result, the government, educators, and parents in Japan became concerned that the pressure-free educational system was not delivering the desired outcomes.

Educational rebuilding began with further reforms to education in 2007 and a reassessment of pressure-free education. The Educational Revitalization Conference recommended that class hours should be increased; governmental education guidelines for teaching were completely revised from 2011 to 2013 (MEXT, 2011a). Table 4 shows the number of classes per week before and after the period of pressure-free education (MEXT 2017b). The number of classes increased to about $93 \%$ the level at the beginning of the relaxed educational reform period. These changes seem to indicate that the era of relaxed education has ended. MEXT has emphasized that the new curriculum guidelines underline the function of education in terms of applicability to future life, not just providing a pressure-free environment.

\section{Why Is Japanese Educational Reform Said to Have Failed?}

In my view, one of the main problems with pressure-free education is that it was driven almost entirely by MEXT and school officials, with no evidence that it would be either effective or an efficient way to develop life skills. It was therefore not supported by private schools, communities, teachers and parents. There was no evaluation index established in advance, and reform was not linked to the high school or university entrance examination system, although the reforms would almost certainly affect outcomes at this stage. Reform has therefore moved on, and the effect of pressure-free education has been ambiguous. 
Japan joined both PISA and TIMSS in the 2000s, to facilitate international comparisons. However, the contents of these surveys have varied over time, making it difficult to judge changes in academic achievements.

Table 1. PISA rankings for reading capacity

\begin{tabular}{llll}
\hline Ranking & \multicolumn{3}{c}{ Year } \\
\cline { 2 - 4 } & $\mathbf{2 0 0 0}$ & $\mathbf{2 0 0 3}$ & $\mathbf{2 0 0 6}$ \\
\hline 1 & Finland & Finland & South Korea \\
2 & Canada & South Korea & Finland \\
3 & New Zealand & Canada & Hong Kong \\
4 & Australia & Australia & Canada \\
5 & Ireland & Liechtenstein & New Zealand \\
6 & South Korea & New Zealand & Ireland \\
7 & Britain & Ireland & Australia \\
8 & Japan & Sweden & Liechtenstein \\
9 & Sweden & Netherlands & Poland \\
10 & Austria & Hong Kong & Sweden \\
11 & Belgium & Belgium & Netherlands \\
12 & Iceland & Norway & Belgium \\
13 & Norway & Switzerland & Estonia \\
14 & France & Japan & Switzerland \\
15 & United States & Macao & Japan \\
\hline
\end{tabular}

Source: National Institute of Educational Policy Research (NIEPR, 2000, 2003, 2006).

Table 2. PISA rankings for mathematical literacy

\begin{tabular}{llll}
\hline Ranking & \multicolumn{3}{c}{ Year } \\
\cline { 2 - 4 } & 2000 & Hong Kong & Taiwan \\
\hline 1 & Japan & Finland & Finland \\
2 & South Korea & South Korea & Hong Kong \\
3 & New Zealand & Netherlands & South Korea \\
4 & Finland & Liechtenstein & Netherlands \\
5 & Austria & Japan & Switzerland \\
6 & Canada & Canada & Canada \\
7 & Switzerland & Belgium & Macao \\
8 & Britain & Macao & Liechtenstein \\
9 & Belgium & Switzerland & Japan \\
10 & France & Austria & New Zealand \\
11 & Austria & New Zealand & Belgium \\
12 & Denmark & Czechoslovakia & Austria \\
13 & Ireland & Ireland & Estonia \\
14 & Liechtenstein & Denmark & Denmark \\
15 & Sweden &
\end{tabular}

Source: National Institute of Educational Policy Research (NIEPR, 2000, 2003, 2006).

Table 3. PISA rankings for scientific literacy

\begin{tabular}{llll}
\hline \multirow{2}{*}{ Ranking } & \multicolumn{3}{c}{ Year } \\
\cline { 2 - 4 } & 2000 & Finland & Finland \\
\hline 1 & South Korea & Japan & Hong Kong \\
2 & Japan & Hong Kong & Canada \\
3 & Finland & South Korea & Taiwan \\
4 & Britain & Liechtenstein & Estonia \\
5 & Canada & Australia & Japan \\
6 & New Zealand & Macao & New Zealand \\
7 & Australia & Netherlands & Austria \\
8 & Austria & Czechoslovakia & Netherlands \\
9 & Ireland & New Zealand & Liechtenstein \\
10 & Sweden & Canada & South Korea \\
11 & Czechoslovakia & Switzerland & Slovenia \\
12 & France & France & Germany \\
13 & Norway & Belgium & Britain \\
14 & United States & Sweden & Czechoslovakia \\
15 & Hungary &
\end{tabular}

Source: National Institute of Educational Policy Research (NIEPR, 2000, 2003, 2006). 
Table 4. Number of classes per week before and after the period of pressure-free education

\begin{tabular}{lllll}
\hline Academic stage in Japan & Grade & $\begin{array}{l}\text { Before pressure-free } \\
\text { education (up to 1980) }\end{array}$ & $\begin{array}{l}\text { Period of pressure-free } \\
\text { education (1980-2012) }\end{array}$ & $\begin{array}{l}\text { After pressure-free } \\
\text { education (since 2013) }\end{array}$ \\
\hline Elementary school & 1st grade & 850 & 782 & 850 \\
& 2nd grade & 910 & 840 & 910 \\
& 3rd grade & 891 & 910 & 945 \\
& 4th grade & 1015 & 945 & 980 \\
& 5th grade & 1015 & 945 & 980 \\
Junior high school & 6th grade & 1015 & 945 & 980 \\
& 1st grade & 1050 & 980 & 1015 \\
& 2nd grade & 1050 & 980 & 1015 \\
& 3rd grade & 1050 & 980 & 1015 \\
\hline
\end{tabular}

Source: Curriculum guidelines (MEXT, 2017b).

These Indices also do not focus on the goals of pressure-free education, such as problem-solving, but aim to compare academic standards and results among countries (NIEPR, 2003, 2006). There is therefore no comprehensive evaluation of whether pressure-free education caused a fall in academic ability in Japan. Use of these comparisons alone might therefore lead inevitably to the conclusion that pressure-free education is a failure.

Over the reform period, the university attendance rate rose (Note 4). University fees are usually funded by parents, not students, and parents whose children enroll in a prestigious university expect to get a return that exceeds their costs, in terms of both income and social capital. It is therefore likely that when parents judged that the standard of public education was falling, private schools increasingly came to be seen as a good investment to increase both their children's future earnings (return on investment) and their social prestige.

Few private schools adopted pressure-free education. The Regulation of School Education Law sets few restrictions on these schools. Private school education is valued for the freedom it offers, as is home education. Secondary schools operating a six-year integrated school system through high schools had no legal obligation to adopt pressure-free education. There was therefore increased investment in compensatory educational expenses outside school for children in public junior high schools, such as "cram schools".

Figure 1 shows household annual auxiliary study expenses per year from 2003 to 2012, such as private coaching, per child in private and public elementary school, junior high school and high school. The dotted lines show data for children in public schools, and the solid lines children in private schools. The squares show data for children in high schools, the triangles junior high schools, and the circles elementary schools. Private elementary schools were only included in the survey data from 2009 (MEXT, 2004-2013).

Households with children in private elementary schools have the highest auxiliary study expenses, which are assumed to include expenses to prepare for the junior high school exam (Note 5). The auxiliary study expenses of children in public junior high schools have also increased steadily since 2003. It seems reasonable to suggest that these households and families have invested more in additional education to improve their children's future academic achievements (Note 6).

Figure 2 shows the proportion of children at private junior high school from households in each income quintile from 2000 to 2013. The triangles show the first quintile, squares the second, diamonds the third, narrow lines the fourth and circles the fifth (Ministry of Public Management, 2001-2014).

A high proportion of children from households in the highest income quintile attend private junior high school and this proportion is increasing. This evidence shows that the children in high income households were more likely to avoid publicly-funded schools, and instead attend private schools to prepare for the entrance exam to universities. 


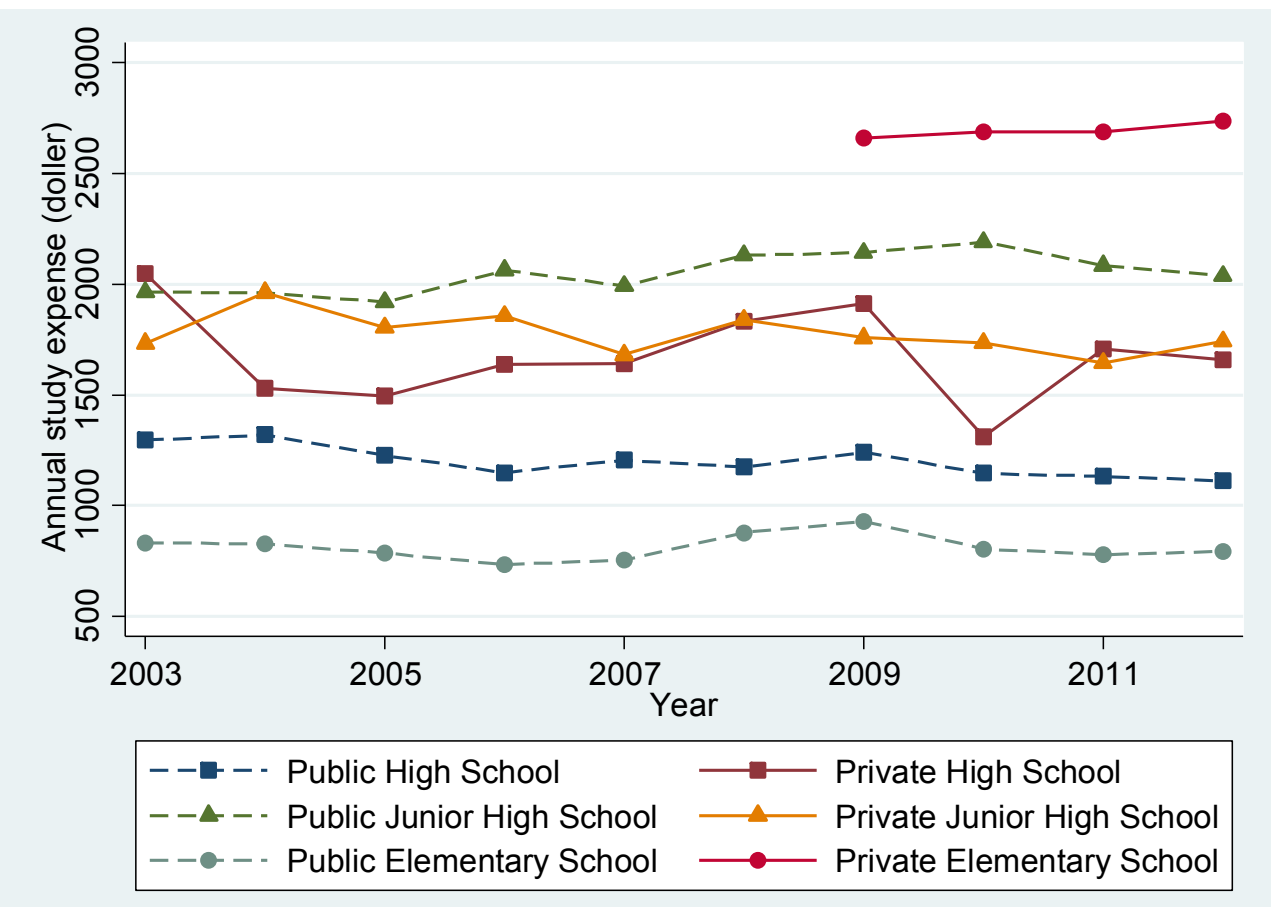

Figure 1. Household auxiliary study expense per year in Japan, 2003-2012

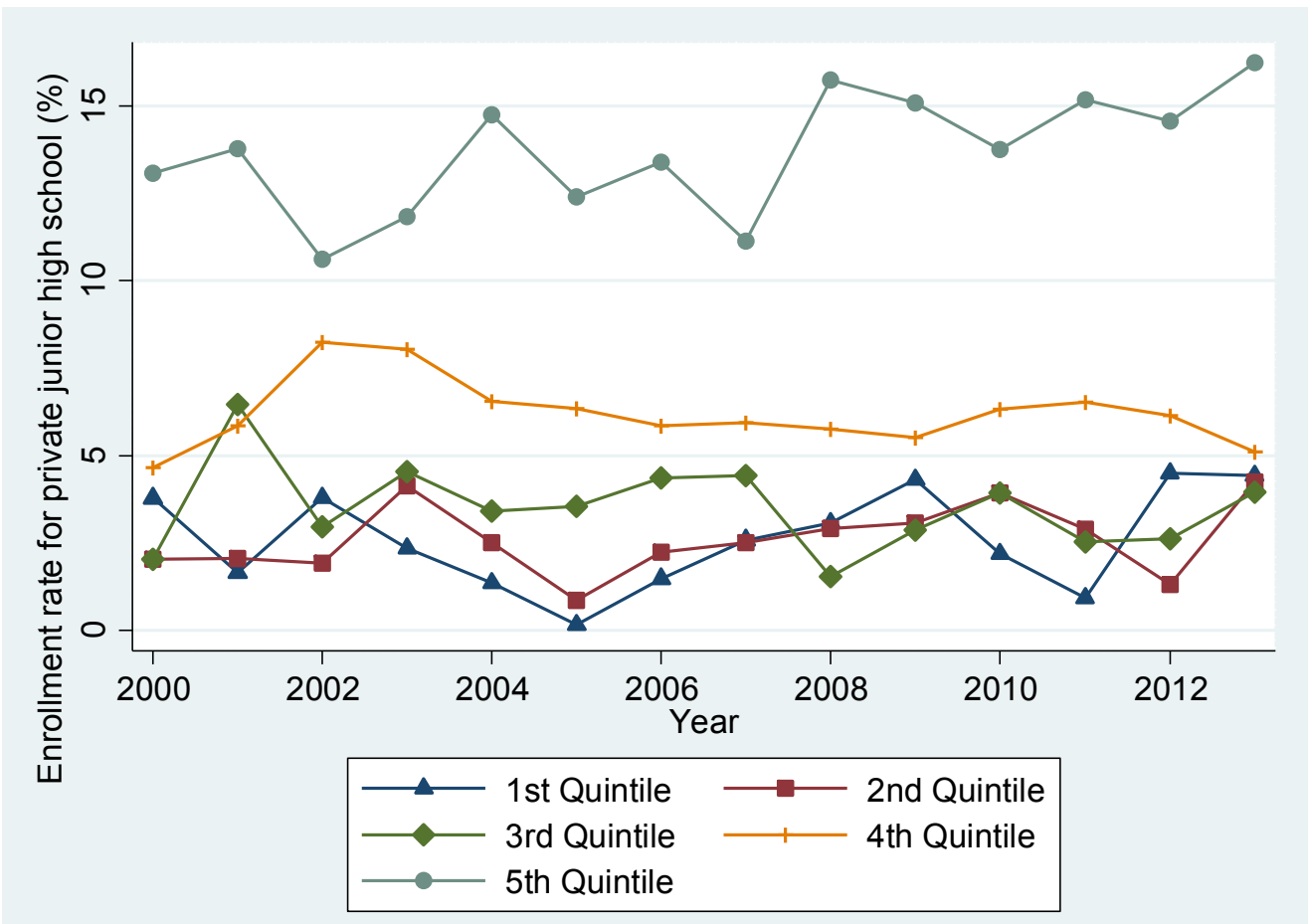

Figure 2. Proportion of children enrolling at private junior high school, 2000-2013, by household income quintile 


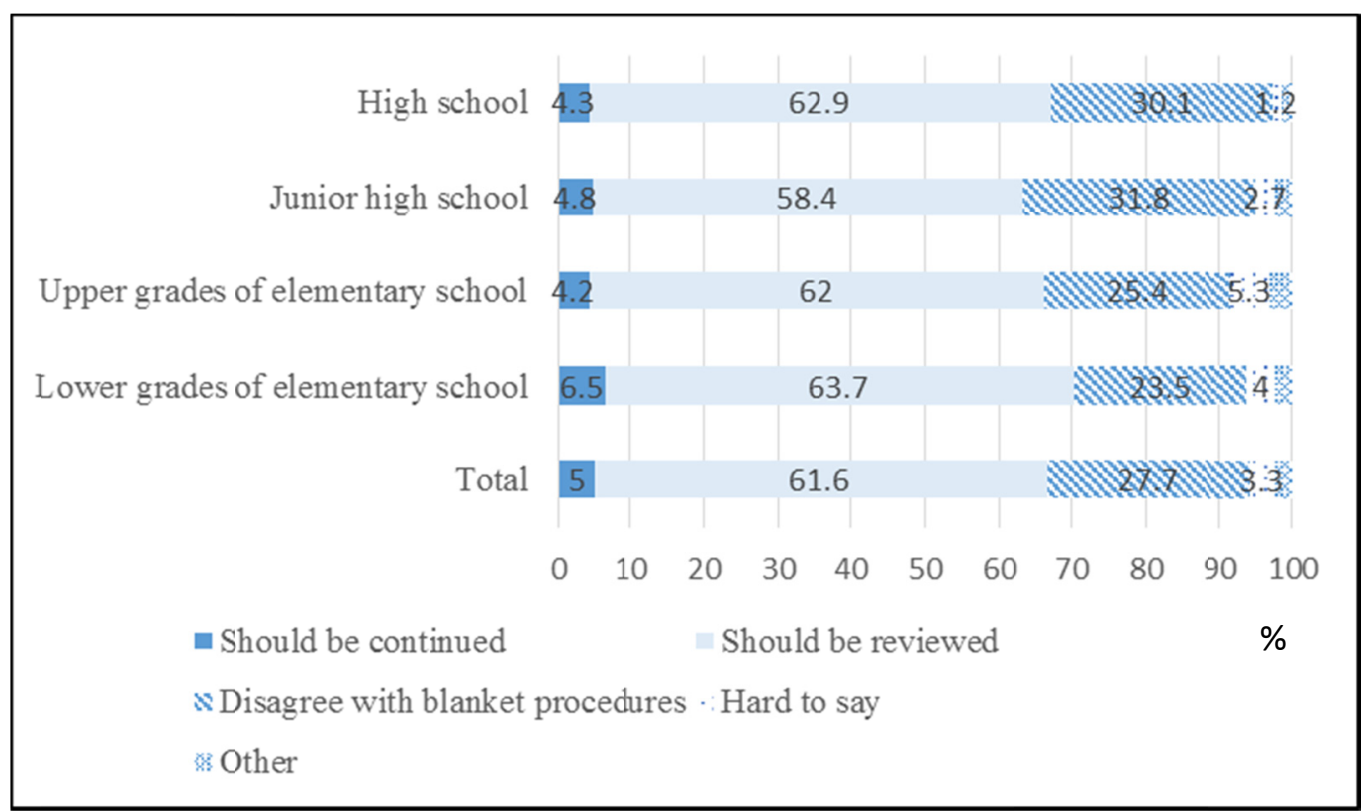

Figure 3. Survey of opinions regarding pressure-free education $(\mathrm{N}=1270)$

Source: Parent survey concerning the school system (Cabinet Office, 2005).

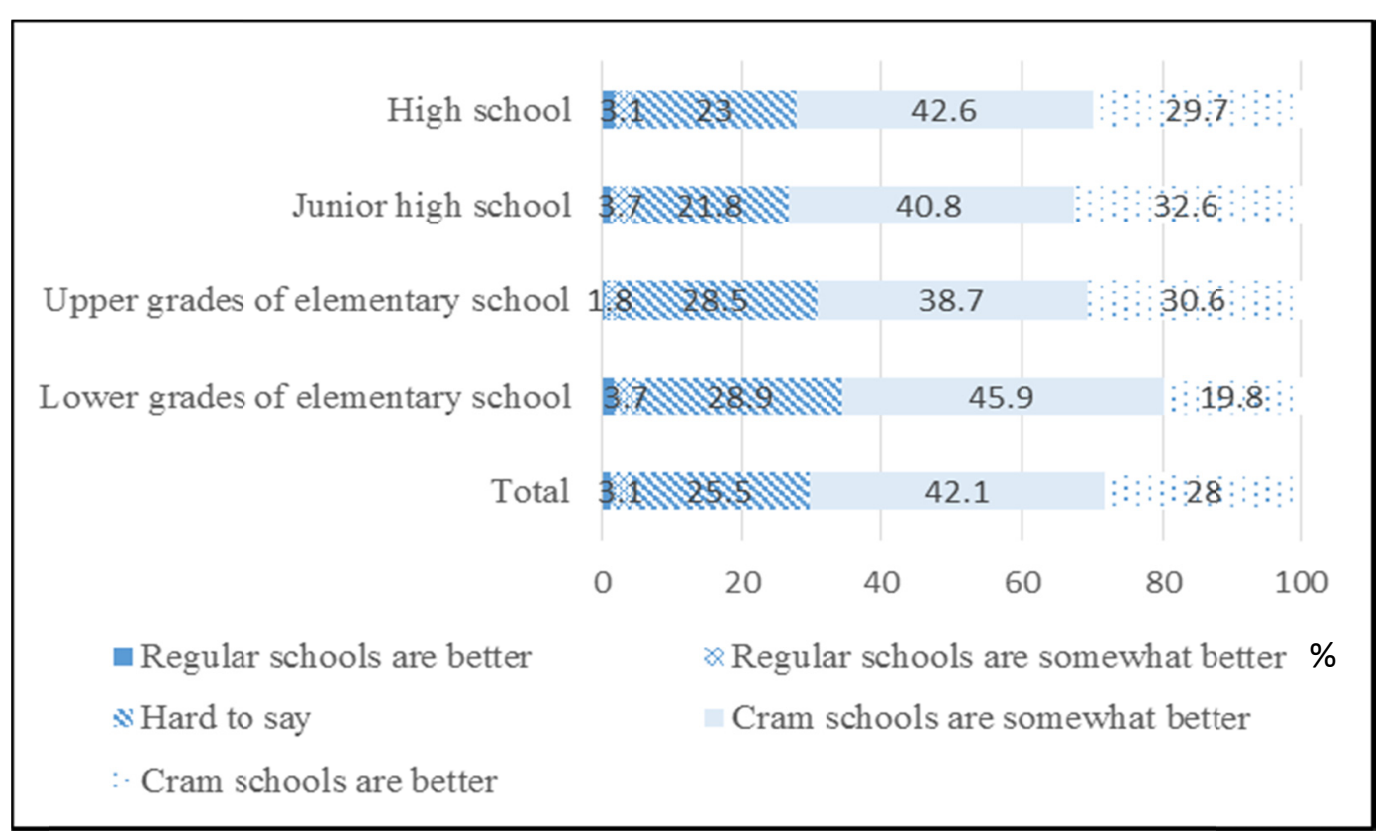

Figure 4. Survey of opinions regarding regular schools and clam schools $(\mathrm{N}=1270)$

Source: Parent survey concerning the school system (Cabinet Office, 2005).

Figures 3 and 4 present the opinions of parents from a survey conducted during the reform period of pressure-free education in 2005 by the Cabinet Office (Cabinet Office, 2005). Figure 3 indicates that for each academic stage, fewer than $10 \%$ of parents believed that pressure-free education should continue. Over $80 \%$ of parents believed that the current educational system should be revised or they felt that blanket procedures were inappropriate. Figure 4 indicates that over $60 \%$ of parents considered cram schools superior. Figures 3 and 4 underline the attitudes of parents toward increasing auxiliary study expenses and avoiding publicly funded schools, as indicated in Figures 1 and 2. 


\section{Lessons for Educational Reform}

In my opinion, management of public educational reform has been inefficient. It has also been hampered because the government has been unable to secure public understanding and agreement for the process. People have viewed reform as ambiguous and uncertain, and its meaning varies for different people. Successful educational reform requires long-term commitment of all those involved, and it is important at each stage to evaluate the progress of the students concerned and to correct and supplement reforms as a result. Above all, I believe that a series of reforms are necessary to bring the system with university entrance examinations in line with the trend with private schools.

Hargreaves (2007) mentioned four domains that need more widespread recognition to overcome barriers to educational reform. These are:

(1) The educational reform is conducted in the context of a complex and confusing broader world;

(2) Educational reform requires social change, and educators have to understand this and take it into account;

(3) There is a political element to the purpose and process of any educational reform; and

(4) Learning, instruction, and thinking all need input into the reform and its goals.

If the relaxed education reform followed these steps, it should therefore have been effective. However, lack of ways to evaluate students' progress means that the effects of this reform are still ambiguous. Evaluation would need to have been carried out at each stage of the educational process. Even within the "pressure-free educational generation" (Note 7), however, the structure and content of education varied with the stages of educational reforms (Note 8). The first children to experience the five-day week during junior high school graduated from university in 2010. It is therefore almost impossible to make a definitive assessment of the precise effects of pressure-free education on them at this stage.

Education is the beginning of the various opportunities in children's lives. Public education is, therefore, and will remain an important subject. All those engaged in education, whether teachers, learners, administrators, researchers, curriculum developers, parents, or members of the community, need to continue to discuss and examine this issue.

\section{Acknowledgments}

We would like to express our deepest gratitude for the financial support from Grant-in-Aid for Scientific Research C, No. 15K03516 and 18K01652.

\section{References}

Arleen, L. (1974). Home investments in children. Journal of Political Economy, 82(2), 111-131. https://doi.org/10.1086/260295

Asahi Newspaper. (2007, December 5). Anxiety for the academic ability. Morning Paper, Japan.

Cabinet Office. (2005). Parent survey concerning the school system, Japan.

Education Development Information Center. (2002). Introduction Course Leaflet for Teaching Position, No. 38, Japan.

Hargreaves, A. (2007). Extending Educational Change: International Handbook of Educational Change. Netherlands: Springer.

Robert, H., \& Wolfe, B. (1995). The determinants of children's attainments: A review of methods and findings. Journal of Economic Literature, 33(4), 1829-1878.

Masakazu, H. (2011). Education production function and class-size effects in Japanese public schools (in Japanese). Global COE Hi-Stat Discussion Paper Series, No. 194, Hitotsubashi University.

Masakazu, H., \& Oshio, T. (2010). What factors determine student performance in East Asia? New evidence from TIMSS 2007 (in Japanese). PIE/CIS Discussion Paper, No. 494, Hitotsubashi University.

Nobuyoshi, K. (2014). The effect of instructional time reduction on educational attainment: Evidence from the Japanese Curriculum Standards Revision. Journal of the Japanese and International Economies, 32, 17-41. https://doi.org/10.1016/j.jjie.2014.01.001

Kohei, K. (2016). Effects of Japanese compulsory educational reforms on household educational expenditure. Journal of the Japanese and International Economies, 42, 47-60. https://doi.org/10.1016/j.jjie.2016.10.003

Ministry of Education, Culture, Sports, Science and Technology (MEXT). (1992). Report of central council, 
Japan.

Ministry of Education, Culture, Sports, Science and Technology (MEXT). (1996). On the way of education in Japan looking forward to the 21st century (Report of Central Council), Japan.

Ministry of Education, Culture, Sports, Science and Technology (MEXT). (2004-2013). Survey of learning cost for children, Japan.

Ministry of Education, Culture, Sports, Science and Technology (MEXT). (2009). The future of children protected by everyone, Japan.

Ministry of Education, Culture, Sports, Science and Technology (MEXT). (2011a). Transition of course of study, Japan.

Ministry of Education, Culture, Sports, Science and Technology (MEXT). (2011b). Essencial point of new culiculum guidelines, Japan. $\quad$ Retrieved from http://www.mext.go.jp/a_menu/shotou/new-cs/pamphlet/_icsFiles/afieldfile/2011/03/30/1304395_001.pdf

Ministry of Education, Culture, Sports, Science and Technology (MEXT). (2017a). School basic survey, Japan.

Ministry of Education, Culture, Sports, Science and Technology (MEXT). (2017b). Culiculum guidelines, Japan.

Ministry of Public Management. (2001-2014). Annual household survey, Japan.

Nakamura, R. (2012). Empirical analysis of the effects of pressure-free education on the academic achievement (in Japanese). Quarterly Household Economic Research, 95, 65-74.

National Institute of Educational Policy Research (NIEPR). (2003). Summary of trends in international mathematics and science study, Japan.

National Institute of Educational Policy Research (NIEPR). (2000, 2003, 2006). Summary of findings from the Program for International Students Assessments, Japan.

Yamamoto, K., \& Muto, A. (1992). Consideration of five-day school week from the view point of leisure time (in Japanese). Bulletin of Faculty of Education, 44, 25-33.

\section{Notes}

Note 1. According to Yamamoto and Muto (1992), the Japanese teaching union was the first organization to mention the importance of pressure-free education.

Note 2. The Education Development Information Center (2002) mentioned that only 43.4\% of private junior high schools introduced the five-day school week system throughout Japan.

Note 3. MEXT (1996) comprehensively explained the aim and necessity of introducing pressure-free education and the point of implementation.

Note 4. According to the School Basic Survey (MEXT, 2017a), the university enrolment rate in Japan rose from $24.7 \%$ to $52.6 \%$ during the period from the 1987 to 2017 .

Note 5. In Japan, many private elementary schools support enrolment at high-level private junior high schools. It is widely believed that combining private elementary school and 'cram school' is a very effective way to obtain a place at a high-level private junior high school. Figure 1 suggests that this route is used by many households.

Note 6. Nakamura (2012) also pointed out that households in large cities had higher expenses than in other cities.

Note 7. The "pressure-free educational generation" is a term used by educationalists and researchers to describe all children born from 1987 to 2004 who attended schools providing pressure-free education during from their elementary and high school years.

Note 8. The "pressure-free educational generation" can be divided three groups covering the three stages of educational reform (Nakamura, 2012).

\section{Copyrights}

Copyright for this article is retained by the author, with first publication rights granted to the journal.

This is an open-access article distributed under the terms and conditions of the Creative Commons Attribution license (http://creativecommons.org/licenses/by/4.0/). 